\title{
MANUAL DE USO
}

\author{
Nicolás Rosa \\ Universidad de Buenos Aires \\ Presidente de la Federación Latinoamericana de Semiótica
}

Todavía hoy dudamos de que el hombre fabrique para hablar enunciados o discursos, si articula la palabra o la lengua, si emite lenguas o bables; lo único que sabemos es que el hombre realiza una actividad que la historia llamó lenguaje y que se organiza por la actividad parlante del sujeto en su registro de lengua y en su faz de inscripción, escritura. El otro fenómeno coalescente es la voluntad del sujeto para darle sentido a esos grafos; los mira, los observa y dice que dicen cosas. Inventó la lectura. Son dos fenómenos que por su banalidad informática y cultural nos parecen simples, pero, si lo volvemos a pensar, son verdaderamente misteriosos. Este hecho dio origen a muchas formas de hablas extrañas (los esperántidos) y de lecturas que se confirman en todos los sistemas de interpretación. En las teorías contemporáneas observamos dos hechos que tienen sucesión temporal: todo es referido a un lenguaje, aunque no adivinemos su sentido, o todo adviene figura que muestra, indica y persiste en significar: todo devie- 
ne hermético y debe necesariamente proyectar una hermeneusis. Todas las formas en que el discurso ha sido considerado, desde la perspectiva lingüística, desde la perspectiva semiótica e incluso desde la perspectiva antropológica o psicoanalítica, concurren a una reflexión sobre dos hechos fundamentales: qué significa y cómo significa. Si empiezo diciendo que dudamos, es porque nada nos garantiza más que el asentimiento o la contradicción del otro, que la secuencia de sonidos que emitimos y que paleográficamente apuntamos, tenga un sentido para mí o para el otro.

Me referiré a una teoría del discurso menos frecuentada en nuestras latitudes y que por razones de actividad profesional y por adhesión ideológica quiero exponer, pues creo que aúna una teoría que concita las posibilidades de analizar la tipología discursiva tanto como el mercado discursivo y permite entender la literatura desde otra perspectiva. $\mathrm{He}$ desarrollado algunos de estos aspectos en las investigaciones a mi cargo y en alguno de mis libros (Rosa, 1990).

En la teoría del discurso contemporánea la sociocrítica, que tiene por objeto la interdiscursividad entendida como sociodiscursividad, puede ser sostenida en dos enunciados teóricos: a) el concepto de escritura y de inscripción social que metaboliza la inscripción subjetiva entendida como datos geográficos, históricos, sociológicos, pero también como una etnografía social, todas las formas del trazado del sujeto en una sociedad determinada en los movimientos de circulación y de detenciones en las llamadas instituciones sociales en donde deja su marca. Y, en esta perspectiva, la literatura - suma de inscripción y de oralidades: una verdadera manufactura de la letra- es un conjunto de enunciados de saberes sociales o socializados pero también una interferencia en esos saberes. Podemos dudar de la legitimidad científica del giroscopio de Foucault, pero como instancia de saber permite una discusión sobre la ley de gravedad que sostiene la imaginación del texto de Umberto Eco. El dato real de la «enfermedad», su clínica, su diagnosis, su pronóstico, su curación y su desliz hacia la muerte generan, en la novela realista, toda una serie de enunciados que soportan tanto la narración como la intriga de la novela realista y de la novela sentimental entre Balzac y Dumas hasta la pavorosa muerte de Emma, castigo somático como símbolo del castigo divino. El pecado, se decía, en una hipótesis visiva, se ve en el rostro, y Dorian Gray, en las variantes modernistas, bien lo sabía.

Epistemológicamente, la novela realista es la enciclopedia de todas las ciencias de la época y narra los distintos saberes en distintos nive- 
les, desde los sistemas de punición y castigo en el orden de la legislación social y en el orden de la moral societaria de la época en donde se tramitan las relaciones de actuación y contraactuación de los saberes legislativos y judiciales, como en las novelas de Balzac, o en las leyes de la herencia en las novelas de Henry James, o las formas asociales del desenfreno y la desorganización en los folletines amorosos de la época. Pero nos interesa señalar ahora la superación disciplinar de un orden retórico basado en las figuras. Nuestra propuesta es reemplazar este orden por una retórica de las hablas sociales, de los dialectos de clase, de los bables fronterizos, qué se dice, qué se escribe, qué se comenta, qué se charla, qué se radiografía en el sector de la vida privada del sector privado de la vida pública, los fenómenos de intermediación entre la vida pública y la vida política, qué se dice pero qué se oculta del sida, partiendo de un presupuesto fundamental: todo discurso remite a otro discurso, lo que implica el conocimiento diferencial de los discursos y, antagónicamente, qué es lo que dicen sin decir en su enfrentamiento a lo real social. El presupuesto disciplinar que manejamos es que en contra de la totalización discursiva visible en muchos teóricos contemporáneos - se habla del discurso político, del discurso científico, del discurso publicitario y sus formas específicas de mostración, pero es difícil demostrar la especificidad de lo específico, es decir, si todo es discurso enfrentado a lo real-, es principio básico sostener que no puede haber especificidades sino una multiplicidad de hablas que hablan de lo mismo en lugares distintos y de lo diferente en los mismos lugares; la permeabilidad sustantiva de los discursos es lo que permite la modificación constante de la fluencia discursiva y sobre todo la disolución de un referente absoluto. Es verdad que las manifestaciones actuales y los niveles de soporte de lo real se inscriben en todas las formas de lo discursivo -incrementación histórica de la letra y del discurso-, sin embargo, nuestra hipótesis marca que lo real, lo no escribible, lo no argumentable, lo inaudito, son formas antagónicas que se enfrentan a las formas de representación discursiva. En el Derecho, no hay forma de representar la idea de justicia, en el discurso literario, Juan José Saer escribe Nadie Nunca Nada; Nadie Nada Nunca, Nunca nadie nada, los tres grados cero de la enunciación: el grado cero del sujeto, el grado cero del objeto y el grado cero del circunstante: el descontar de la narración. En los medios masivos, el fenómeno de retroalimentación de los discursos mediáticos hace que los medios ya no informen ni publiciten, sólo hablan de sí mismos. El periodismo mediático es un periodismo autobiográfico y en primera persona. El 
protagonismo social de algunos discursos marca la política de los discursos en una sociedad pero simultáneamente la subversión constante de los mismos. La compleja tipología de los discursos circulantes desde la oralidad en todas sus formas - las artes de hablar en oposición a las artes de escribir de Walter J. Ong, a las que yo agregaría, el arte de leer (Ong, 1982; Rosa, 1997) — la conversación y lo conversacional (en Puig), el rumor, la charla (en Fray Mocho), el chisme y su circulación (en Laferrère o en David Viñas: Las de Barranco o Cuerpo a cuerpo), o el chiste (en Cancela), hasta los grandes géneros que fundan la hegemonía de los discursos: el de la política, el de la religión (Bourdie, 1971), los de la ciencia, etc., que presiden en relación de homogeneidad y subordinación los discursos menores como los de la costumbre, los de la doxa social, familiar, etc. Esta subordinación implica fundamentalmente una relación de distribución más que una relación de valor. El fenómeno de una mayor incidencia en el registro social depende de la historicidad de los fenómenos discursivos. Si persistimos en nuestros ejemplos, lo que se dice y lo que se escribe (pero también lo que se escucha) sólo puede definirse en función de lo que no puede decirse o escribirse en una sociedad determinada. Los tabúes y censuras discursivas marcan el lugar de los discursos pero también su exclusión. Es verdad que el discurso narrativo en la versión novela elabora retóricas para intentar salvar estos escollos (la perífrasis o la paráfrasis, ambas pueden ser enigmáticas, y todas las formas de elisión y de alusión). La explosión actual del discurso sexual, en todas sus variantes, repone sobre la escena discursiva varios fenómenos: el problema del género y del género social, el discurso sobre el sida, el discurso sobre los gay y lesbianas, como antes fue el de la prostitución, el discurso feminista, el discurso de la etnicidad, etc. permite en los fenómenos de superficie una extensión discursiva e imaginaria polifónica, que encubre fenómenos de clausura, silencio, reticencia, mudez y ostracismo de otros discursos, como, por ejemplo, la reivindicación clasista encubierta teóricamente por la disyunción «pobres o ricos» que iguala la reivindicación con la justicia distributiva.

En la contemporaneidad, los discursos que se entrecruzan y se convierten en motivo de causa productiva del discurso social y del discurso literario pueden ser determinados de esta manera: Discursos de procesos de enunciación: afirmación, negación, conjeturales, apodícticos, sentenciosos; discursos de explicitación: fenoménicos, científicos, dóxicos, regulatorios, justificativos; discursos de predicación: testimonios, prédicas, probativos, judiciales, sentenciosos, interpelati- 
vos, sermonarios, etc.; discursos dóxicos: el chisme, el chiste, la charada, el rumor, la calumnia, los lugares comunes morales y de la moral común, los clichés, los refranes, los vaticinios, la glosa de la vida cotidiana y las versiones; discursos de aplicación: técnicos, artesanales, artísticos, moralizantes, científicos, dóxicos; discursos de ejemplificación: éticos, moralizantes, probativos, pseudocientíficos, dóxicos. La constelación de los discursos circulantes exime de una jerarquización valorativa. Esa jerarquización generalmente es debida a las macro y micro-ideologías suspendidas en la vida social y a la jerarquización endóxica de los sujetos sociales. La clasificación de estos discursos deja de lado el grado de intensificación de los mismos de acuerdo con las prácticas sociales y que por ende pueden modificar su estatuto y su régimen de variación. Pongamos por caso, la medicina ocupa el lugar dentro de los discursos científicos pero simultáneamente el lugar de los saberes cristalizados en la cura popular, los manosantas, los curas sanadores, las brujas o tiradores del tarot o la medicalización del desvío sexual en la clandestinidad —a medias pública- destruyendo los lugares sombríos de fin de siglo o de la época victoriana, por ejemplo, en Cambaceres, o el estigma de la degeneración en las prostitutas que reaparece en Manuel Gálvez, en donde se entrecruzan los discursos de la psiquiatría del momento, el discurso médico-administrativo, el del médico alienista y del higienista social, cuyos temas básicos son la prostitución, la histeria, el safismo, la novela erótica y los elementos de la utopía libertaria de las feministas de fin de siglo (Angenot, 1986).

El símil del espejo ha sido desde siempre la figura de la creación artística como reflejo de la copia de la realidad sobre el principio de la mímesis artística, vinculada a la representación realista sobre la base de la objetividad. La otra imagen, la de la lámpara, según Abrams (1962), considera que la realidad está tramada de aspectos según la perspectiva del artista y por ende vinculada con las artes intimistas, simpáticas, que exigen una representación perspectivista de los fenómenos. A partir del surrealismo y del psicoanálisis — sin entrar a considerar otras relaciones más que la histórica- las formas de representación han ido cambiando hasta alojarse en sistemas de presentación, de copia, de mimetismo, incluso de plagio. Las artes figurativas son ahora artes de des-figuración. Los códigos, a partir de nuevas canonizaciones, se han quebrado y las artes del lenguaje, pretendidamente comunicativas, se han vuelto contra-comunicativas; la visión se ha vuelto estereoscópica: el espejo se ha quebrado, la lámpara se ha roto. 
La interdiscursividad de los enunciados puede constituir nuevas formas de análisis de las formaciones discursivas y de las formas discursivas en el registro literario: lo dicho y lo no-dicho, lo textualizable y lo no-textualizable marcan los límites de los enunciados, no una línea temática propia del estudio de las fuentes de procedencia estilística (De Ernst Curtius a Cesare Segre, de Dámaso Alonso a Bousoño), sino una constelación de enunciados de procedencia diversa fijados en un momento de la historia. Esta constelación siempre es efímera pues está sujeta a dos principios: a) es una construcción del observador - diría del observante para tratar de desujetivizarlo- y por ende está sujeto a las determinaciones específicas que la conforman - determinaciones concientes e inconscientes- y b) está conformado por la doxa social que la instituye: el sujeto científico es el intento mayor del sujeto para desprenderse de los enunciados doxísticos de una sociedad, cristalizaciones máximas, lugares comunes, presupuestos ideológicos, tipologías que constituyen, en su concretización, ideologemas que circulan en el campo social y en el campo investigador. Pongamos como ejemplo, dentro de nuestra perspectiva, la teoría de los géneros desde Aristóteles, Horacio, Boileau, Malherbe, Guez de Balzac, hasta las formas semióticas de Jakobson y la lógica de los géneros en Kate Hamburguer (1986) y en el nivel textual mímesis, copia, falsificación, versión, similitud, que repone la contemporaneidad, irónicamente en Roland Barthes y taxativamente en Harold Bloom.

Podríamos precisar nuestro enfoque señalando los diversos discursos que pueden registrarse en una sociedad determinada generando una relación interdiscursiva en el nivel de la circulación e inter-extra textual en el nivel del texto social. Estas configuraciones están presididas por dos leyes discursivas fundamentales: las múltiples referencias que permiten las relaciones complejas de intersección, disposición y entrecruzamiento en diversos grafos de las potencias discursivas, presididos por el trabajo de textualización, de ficcionalización, los efectos de texto y el aspecto valor del texto, trabajo sobre la lengua y sobre el significante. Si tomamos una novela de Cambaceres, puedo pensarla como un entrecruzamiento de saberes sociales que se condensan en enunciados y máximas que circulan en determinada época. Los enunciados de la moral societaria que van desde 1870 a 1890 en donde están presentes todos los saberes de la época: el discurso sobre la prostitución y las formas de la sociabilidad, que vemos en los textos de Mansilla que proviene de una secuencia histórica anterior, o los discursos sobre la sociología y criminología de ingenieros, o las leyes de profilaxis social, las 
formas médicas de la tocología, las formas carcelarias de la represión, el discurso psiquiátrico y manicomial de Ramos Mejía, la dactiloscopia de Vusetich y las formas de identificación y de identidad, el discurso de la inmigración y su contraataque discursivo en la Ley de Residencia como discurso justificatorio y regulatorio de Miguel Cané, la simulación y el disimulo en la vida ciudadana que muestra la importancia del salto desde La Ciudad Indiana de Juan Agustín García a La Bolsa de Julián Martel, pasando por La Gran Aldea de Lucia V. López, las fórmulas del lenguaje en las calles, como vemos en Fray Mocho y en los barrios donde el lenguaje del delito, núcleo inicial de la «lunfardía», será reconstituido por Dellepiane, que encuentra su exaltación en las novelas tipológicas como Irresponsable de Podestá, o atípicas como Libro Extraño de Sicardi, permiten armar un dispositivo discursivo de lo decible y de lo legible en una época, sobre el presupuesto de que no son códigos, cánones o estilos, o géneros, sino funciones que se modifican rápidamente en el campo histórico pero también de escritura a escritura. Lo literario es el enunciado que migra, acepta, transforma, diverge, modifica, pero que también resiste las puestas discursivas y los dispositivos de los arcaísmos y de las novedades, de los aparatos de equilibrio de los niveles discursivos, de las concretizaciones dóxicas y de los estereotipos sociales que aparecen como exceso de la significación que tarde o temprano operará contra la hegemonía discursiva. La razón última de la literatura dentro de los discursos sociales es que es intraductible a cualquier otro discurso; esa es su única especificidad.

Las formas generales de la discursividad son la narración y la argumentación; ambas dos reaparecen, se disimulan, se conectan, se superponen e incluso se interpretan en el discurso de la novela, que presuponemos taxativamente narración. La modificación diacrónica de estos géneros discursivos, en el sentido bajtiniano del término, permiten trazar una historia de la novela y en particular de la discursividad argentina como multidiscursividad. Pero nos interesa ahora reafirmar los registros disciplinarios de nuestra analítica discursiva.

\section{HACIA UNA SOCIODRAMÁTICA: EL SUJETO DE LA EPIGRAFÍA SOCIAL}

La herida producida al sujeto en las Ciencias Sociales contemporáneas, sobre todo por el psicoanálisis pero también por ciertas formas 
de la sociología (Georges Simmel) y de la antropología cultural (Goffman), que quiebran la sustantividad de la noción de sujeto y la colocan en el plano de una dualidad constituyente, permite volver a leer desde nuevas perspectivas al sujeto unitario de la psicología tradicional a partir y a través de sus fallas: el sujeto-otro de una nueva etnografía como conformación de la otredad de otras culturas: para Montaigne en los Essais, la China, hasta Lévi-Strauss (los bororos brasileños), o los «persas» para Montesquieu o los «árabes» para Pierre Loti, y en el nivel macro, América para Europa, o la Europa Balcánica para la Europa Meridional; el sujeto fenomenológico del devenir dialéctico hegeliano, o el otro como garantía del sujeto en Sartre, o la otredad extrema del sujeto psicoanalítico en Freud o en Lacan como otro recinto del código o de la ley, o la mismidad como fundante de una alteridad humana en Lévinas, ha generado una concepción de la entidad sujeto dividida, escindida, clavada en su perpetua evanescencia, la pura anulación en su propio decir (Jakobson, Ducrot), y constituye hoy la fórmula trascendental de toda teoría del enunciado y del discurso.

Las formas y las localizaciones en el orden descriptivo-analítico arman un sociograma (Duchet, Angenot, Robin), pero simultáneamente un sociodrama en donde se entrelazan la topografía del escenario de demografías sociales - demografía de las poblaciones narrativas- y una topología de la pasión de los actantes sociales. La topografía de las poblaciones narrativas y sus secuencias (tránsito, camino, peregrinaciones, idas y vueltas, etc.) pueden relevarse a partir de su organización en grafos para señalar indicialmente las formas de su estructura móvil: concentración-dispersión, grupo, grupo extendido, familia, las novelas de familia y su ascendencia y descendencia en la novela realista francesa (los Rougon-Macquart en Zola), novelas de la clase como En busca del tiempo perdido de Proust, o Sin rumbo de Cambaceres, las novelas de grupos sociales como Los albañiles de Vicente Leñero, la narración de épicas miserabilistas como en Elías Castelnuovo, las novelas de desclasados como en Arlt, las novelas de épicas nacionales como en Tolstoi, o las novelas de caminantes, desde la picaresca tradicional (Lazarillo de Tormes), la picaresca política de Payró, pasando por El Lazarillo de Ciegos Caminantes de Concolorcorvo, cuyo modelo es el Viaje político-científico de Malaespina. La decadencia de las grandes familias, cuyo paragrama reproduce la historia de los reyes, pasando de la vía regia a un camino real y de la genealogía a la cronología, y de una sucesión a una evolución, de una estirpe a una prosapia, y de un método hagiográfico a un método expe- 
rimental (Claude Bernard). O el unanimismo de Jules Romains (Los hombres de buena voluntad), inventando una difusa fantasmática del alma colectiva preanunciando, en niveles sociológicos distintos, la consideración del imaginario colectivo y de la colegiación en el orden social. Y en épocas actuales, el relato de vida imaginaria del sujeto en la «novela familiar» (actante colectivo) del neurótico en Freud, en donde se enlazan las fantasías de origen y los fantasmas de creación y del propio engendramiento (autogeneración), o el primer engendrado (el unigénito) y el último de la estirpe, elaboran nuevos programas narrativos como el de la primacía y el de la secundariedad (el hijo segundón) y los relatos de la extinción por degeneración o desaparición propios de la novela realista y naturalista. La «enfermedad» que la provoca es generalmente una enfermedad social, la tuberculosis, la sífilis, y en las postrimerías de nuestro siglo reaparece un elemento fundamental del sociodrama: el sida como peste, reponiendo sobre la nomenclatura histórica los fenómenos de la destrucción amenazante y apocalíptica de los fines del milenio. (El tema de la peste, desde el drama edípico hasta La peste de Camus, pasando por el Diario de la peste de Defoe y los virus electrónicos que pueblan el ciberespacio, prueba que la peste es siempre «aquello que viene de afuera», el Alienus.)

Llamamos narremas a los enunciados narrativos de diferente extensión que se construyen sobre el material narrativo preexistente - la historia de la narratividad, sus inflexiones, sus recursos estilísticos, sus estrategias narrativas, etc.- y que integran la materia prima del discurso con el que la narración edificará su entramado sintáctico y el registro de sus funciones temáticas. Sus rasgos definitorios son, por lo tanto, su existencia pretextual y su integración intertextual. Estos enunciados narrativos mínimos constituyen conjuntos narremáticos integrados por unidades móviles de diversa extensión compuestas por dos o más narremas. Llamamos tactemas a los nexos articulatorios de los narremas. La relación sintáctica de los conjuntos de narremas está presidida, como habíamos señalado, por leyes de hegemonía y de subordinación con dos determinaciones: a) la apropiación que realiza el enunciante y las modificaciones que produce en esta apropiación (aceptación, rechazo, impugnación, conservación, etc.), que darán las formas que luego la crítica o la historia literaria formulará como vanguardista, progresista, arcaísta, revolucionaria, innovadora o renovadora, y la recuperación en la transmodernidad de los términos «primitivo», «tradicionalista», «canónico», etc. Estos conjuntos narremáticos están determinados por el programa narrativo. El conjunto de narre- 
mas, a su vez, constituye verdaderos ideogramas de la narración, que pueden ser leídos como ideologemas narrativos de los otros discursos del entramado social. Por ejemplo, el conjunto de narremas románticos y en núcleos más amplios, modernista, del predestinado, señalamiento, destino aciago, triunfo repentino, infortunio y rápida fortuna y descenso vertiginoso de la esfera psíquica (morbo melancólico, triste$\mathrm{za}$, sospecha de locura, enfermedades prohibidas, temor y rechazo de lo social, etc., lo convierte en un predestinado, que en la óptica realista constituirá una enfermedad social y los estigmas de la degeneración (herencia, demencia), y en el plano societario, el extraño social, producto de un atavismo donde se entrecruzan Lavater y Lombroso y la novela realista. Digamos, una cierta libertad instintiva con respecto a la ley en Martín Fierro acabará en el instinto desatado - la ley de la sangre que pide sangre - en Hormiga Negra.

A diferencia del enunciado narrativo mínimo de la narralogía (actante + función), el narrema, que consideramos una unidad ideologramática, se define intratextualmente en los enunciados del programa narrativo de la obra e intertextualmente en relación con los discursos circulantes en la época. La distinción entre narremas causales e indiciales propuesta por Marc Angenot con fuerte influencia barthesiana, presupone otro tiempo de estructuración narrativa mucho más fuerte y quizá inmanente. El problema consiste en que podemos suponer, y hay pruebas que lo manifiestan, que los programas narrativos del realistmo están modificándose rápidamente. La narración contemporánea no narra sino que presenta, o en otra dirección finge que narra con fórmulas tradicionales para encarnar significaciones distintas. Si ponemos enfrente la novela Récits Tremblants de Lyotard y los textos primeros de Saer, ambos intentan no-narrar un angustioso combate para que el tiempo no pase, para que la intriga no suceda, para que la lectura no se mueva. En la literatura más actual, los narradores argentinos vuelven a narrar, expresan las formas narrativas en su propia esencia, pero siempre nos advierten que están narrando, que siempre están allí rompiendo el «encanto» de la novela realista -que cumplía estrictamente el programa narrativo del «estar allí de la ficción» sin régimen autoral-, cumpliendo con la tentación extraordinaria de creer que la obra era nuestro propio pensamiento que leíamos. Quebrados los sistemas de identificación de la novela realista, el lector real es siempre un intruso y, para que el sociograma se apoye en un sociodrama, debe apelar a la historia, a la autobiografía, a la ficción política, a los relatos de la vida cotidiana de la televisión, sin épica y sin héroe. 
En algún momento habíamos establecido, en la narración de la vida de Sarmiento, el narrema Joven pobre «pero inteligente» (podríamos pensar en otras variantes del paradigma - pobre pero honrado, pobre pero limpio, etc., que tienen consistencia social) - que revela los núcleos semánticos que van a generar dos relatos: la «historia» de la pobreza y la «historia» de la formación de esa inteligencia, y un tactema adversativo (pero), que opera las bifurcaciones del programa narrativo y, potencialmente, su multiplicación y reemplazo por otros narremas más desarrollados, opuestos o contradictorios con el inicial. Este narrema se subordina al narrema hegemónico dentro de la ideología y la economía narrativa de la época: «ascenso en la sociedad», narrema del discurso sociológico: movilidad social, igualdad de oportunidades, etc. - y a su vez subordina un narrema de obstáculos y pruebas, que generan una retórica de signos dilatorios y prospectivos: el esfuerzo y los distintos fracasos parciales y los signos anticipatorios que pueden ser proyectos realistas sobre la base de lo que se quiere ser el futuro, de orden probabilístico o fantasioso en relación con el régimen de la fortuna, signos prodigiosos, datos reveladores o signos preventivos que generan modificaciones en los comportamientos de los personajes- Cada uno de estos narremas y el programa narrativo consecuente se modifican en función de una acentuación de cada uno de los sintagmas de los enunciados y los regímenes de adversión generando modificaciones en los géneros: la novela realista, la novela folletinesca, la novela sentimental, la novela gótica o la novela policial, o modificando sustancialmente las entidades de modo que genere nuevas entidades narremáticas. Esto permitiría estudiar las modificaciones históricas de las formas de narrar en una época en relación con las modificaciones de los programas narrativos del discurso histórico, del discurso antropológico, etc., y en última instancia revelar cuáles son las condiciones de producción de los relatos en relación con las conformaciones sociales que los sustentan.

Estas formulaciones generan interrogantes sobre las formas en que circula y se significa el discurso poético; en suma, la poesía, en el sentido en que la entendían los románticos de Jena, como el inicio y el culmen de toda escritura literaria suspendida ante los géneros y por momentos renegando de ellos. Si nos permitimos hacer un rápido recorrido por la historia de la poesía y nos detenemos en el Poema de Parménides o en De rerum natura de Lucrecio, pasando por La Divina Comedia o Tasso, la poesía lírica desde Anacreonte y la lésbica Safo hasta la desbocada Alejandra, hijastra de Olga Orozco; si pensamos en la poesía desalmada que hay en Marguerite Duras, pero antes en Rilke 
y Pound y en la épica virgiliana de Eliot y en la peligrosa poesía de Edgar Allan Poe y luego en las epicidades revolucionarias de Einsestein o de Kubrick, podemos sugerir que la poesía no tiene género, ni quizá estilo, sino básicamente es un sistema de interferencia tanto del mundo natural como del mundo racional y del mundo literario, si entendemos que los mundos sólo son órdenes de la razón mientras que lo poesía los desdeña. No es que la poesía sea irracional; está fuera del cómputo de la razón; interfieren tanto la razón como la sensibilidad. No es producto de la lógica ni del tortuoso ensueño romántico; es sencillamente una cosa, un dato último, con la que a veces, muy pocas, tropezamos en nuestro camino.

\section{Referencias bibliográficas}

Abrams, M. H. (1962). El espejo y la lámpara. Buenos Aires: Nova. ANGENOT, MARC (1986). Le cru et le faisandé. Bruxelles: De. Labor.

ANGENOT, MARC (1988). «Rethoriques du discours social». En Réthorique et Littérature 19.

BOURDIEU, PIERRE (1971). «Génèse et structure du champ réligieux». Revue Française de Sociologie 12/3.

BOUVERESSE, JACQUES (1995). «Règles, dispositions et habitus». Critique (Pierre Bourdieu).

Duchet, Claude (1988). «Médiations du Social». Litterature.

HAMburguer, Kate (1986). Logique des genres littéraires. París: Du Seuil. ONG, WAlter J. 1987 (1982). Oralidad y Escritura. México: FCE, 1987.

RoBIN, REGINE (1989). Le roman memoriel. Longueil (Montréal): Le Préambule.

RosA, Nicolás (1990). El arte del olvido. Buenos Aires: Punto Sur.

- (1997). La lengua del ausente. Buenos Aires: Biblos. 